\title{
Effects of Sucrose Intake on Spermatophore Mass Produced by Male Swallowtail Butterfly Papilio xuthus L.
}

\author{
Mamoru Watanabe* and Masayo Hirota \\ Department of Biology, Faculty of Education, Mie University, Tsu, Mie 514-8507, Japan
}

\begin{abstract}
A one-day old virgin male of the swallowtail butterfly, Papilio xuthus, requires about $50 \mathrm{~min}$ (at ca. $26.5^{\circ} \mathrm{C}$ ) to transfer a spermatophore into the bursa copulatrix of a virgin female. Under such conditions, the spermatophore mass averages $4.7 \mathrm{mg}$, but is much smaller at the male's second mating (about a half). The energy stored during the larval stage is only enough to produce 1.5 spermatophores of the average size of the first mating. There is a positive correlation between adult male sugar intake and spermatophore mass at the second mating. To produce a spermatophore in a second mating that is the size typically produced by virgin males, a male must ingest $390 \mathrm{mg}$ of sucrose solution (20\%), which would take an estimated 4.3 days. If a large spermatophore is advantageous for mating, males are expected to have a period after mating when they feed but do not search for mates.
\end{abstract}

\section{INTRODUCTION}

Many lepidopteran adults feed on a variety of food sources such as pollen (Boggs and Gilbert, 1979), nectar (Murphy et al., 1983) and so on. Nectar is composed mainly of sugars with trace amounts of free amino acids (e.g. Baker and Baker, 1973). Heinrich and Raven (1972) stated that nectar is the only energy source for adult butterflies though it is low in protein content. Adults of the swallowtail butterfly, Papilio xuthus, feed exclusively on nectar (e.g. Watanabe et al., 1988), and do not feed at mud or dung, which are potential sources of sodium and nitrogenous compounds (e.g. Arms et al., 1974). Most laboratory studies evaluating the influence of sugar consumption on adult Lepidoptera report that it enhances female egg output (e.g. Stern and Smith, 1960; Watanabe, 1992). Feeding on sugars may also increase longevity (Carroll and Quiring, 1992). However, there is no report examining whether the sugar affects the quantity or quality of male ejaculates.

Among butterflies, the ejaculate contains spermatophore in addition to sperm. These ejaculates are made up of lipids (Marshall, 1985), protein (Boggs and Gilbert, 1979) and sugar (Watanabe and Sato, 1993), which are used by females in oogenesis and somatic maintenance (e.g. Watanabe, 1988; Boggs, 1990; Wiklund et al., 1993). Consequently, males not only contribute sperm but also provide a material investment in the production of eggs. Male ejaculate must affect the fitness of each sex and subsequently the evolution of mating systems (Boggs and Watt, 1981; Dewsbury, 1982; Kaitala and Wiklund, 1995).

Male ejaculate investment plays a crucial role in mating patterns of polyandrous butterflies, as a female's mating fre-

\footnotetext{
* Corresponding author: Tel. +81-59-231-9259; E-mail: watanabe@edu.mie-u.ac.jp
}

quency is affected by ejaculate size, with large ejaculates delaying female re-matings longer than small ejaculates (e.g. Sugawara, 1979; Oberhauser, 1992; Wiklund and Kaitala, 1995). This effect may lead to a selection favoring the production of large spermatophores. However, the production of ejaculate is costly (e.g. Svärd and Wiklund, 1986; Oberhauser, 1988; Bissoondath and Wiklund, 1996a) and limited (Rutowski and Gilchrist, 1986). As expected, the rate of male re-copulation in a given species depends on that species' specific mating frequency (Kaitala and Wiklund, 1995), so that males in polyandrous species deliver large second ejaculates much sooner than males in monandrous species (Svärd and Wiklund, 1989).

The size of a spermatophore is also related to its reproductive value to females. Even among virgin males there is intraspecific size variation in spermatophore (Sims, 1979; Rutowski and Gilchrist, 1986). However, a male's capacity to produce multiple ejaculates during his life is limited (Svärd and Wiklund, 1986, 1989). Both spermatophore size and nitrogen content decline between the first and second mating (Oberhauser, 1992). In males spermatophore size may be influenced by the number of successive matings if resources for ejaculate production are limited (e.g. Carroll, 1994). In addition to mating history and male body size (e.g. Svärd and Wiklund, 1986; Lederhouse et al., 1990), the time between previous matings (Sims, 1979) and age (Oberhauser, 1988) have also been found to significantly affect spermatophore size.

In the present study, we measured the quantity of ejaculate produced by virgin and experienced males that had and had not been fed sugar following adult emergence. These results will be discussed in view point of the male reproductive strategy. 


\section{MATERIALS AND METHODS}

We mated males with either one or two virgin females of $P$. xuthus, and assessed the effect of male characteristics (mass, age, and quantity and quality of diet) on copula duration and the mass of ejaculate. All animals were obtained from a stock culture reared in the laboratory at room temperature in the summer of 1996. Most of them were offsprings from the 1st emergence of 1996 in Tsu City, Mie Prefecture.

More than 500 males were reared for this study, in which the following trend was ascertained: in P. xuthus (Watanabe, 1988; 1992) and other butterfly species, the size of laboratory-reared adult butterflies is often smaller than that of adults taken from natural populations. Accordingly, to minimize the effect of small body size, only males with a weight of more than $400 \mathrm{mg}$ were used (mean $449.8 \pm 4.1 \mathrm{mg}$ ). The forewing length of each male used was, therefore, more than 50 $\mathrm{mm}$ (mean $53.4 \pm 3.0 \mathrm{~mm}$ ), regarded as similar in size to natural populations (c.f. Watanabe and Nozato, 1986).

Males of $P$. xuthus typically eclosed every morning, and most of them evacuated excrement during wing extension. The weight of the adults was measured and the males were assigned randomly to three feeding regimes: (i) water only; (ii) $20 \%$ sucrose solution; and (iii) unfed. We chose $20 \%$ sucrose because this concentration produces an optimum rate for energy intake (e.g. Pivnick and McNeil, 1985; Watanabe, 1992; Muraoka and Watanabe, 1997) and sucrose is the dominant sugar in nectars consumed in fields by swallowtail butterflies (Watanabe et al., 1988). In addition some unfed males were examined. Individuals were taken from the populations as adults following their emergence and segregated by sex.

Males were maintained in flight cages $(30 \times 40 \times 45 \mathrm{~cm})$ while females were kept individually in envelopes (14L10D light cycle in room temperature of $26-27^{\circ} \mathrm{C}$ ). Adults were weighed just after emergence, therefore characterizing adult body mass. Beginning on the day after eclosion, males were fed for 3 min around the noon every day. The sucrose intake of each male per day was determined by weighing him before and after feeding.

Because a male's mating ability on the day of eclosion is low (e.g. Sims, 1979), we only hand paired males aged at least one-day with virgin females in the morning. Hand pairing is widely used in the laboratory rearing of butterflies (e.g. West, 1983; Scriber and Lederhouse, 1988). The technique we used was to bring the tips of their abdomens together, squeeze the male in order to open his claspers and then join him with the female. When the two were joined in tandem, they were removed to a small cages and the copula duration was recorded. Immediately after copulation, the females were decapitated and dissected under a stereo microscope to measure the weight of ejaculates in the bursa copulatrix.

All means are shown with their standard errors. All weights were determined on a microbalance to the nearest $0.001 \mathrm{mg}$.

\section{RESULTS}

The abdominal cavity of males just after emergence was mostly filled with fat bodies and a relatively small air sac. Since the fat body was used for somatic maintenance, it gradually depleted and the volume of the air sac increased with aging. It came to fill half the abdominal cavity in 5-day-old males that fed on water.

Since it may take 1 day to completely harden the whole body, all adults aged 1 day decreased to $80 \%$ of their initial weight (Fig. 1). Unfed males lost weight as they aged. All died within 3 days. The weight of these males just after death was about $65 \%$ of that of 0 -day-old ones. Males which were fed on water also became lighter as they aged in a similar way to the

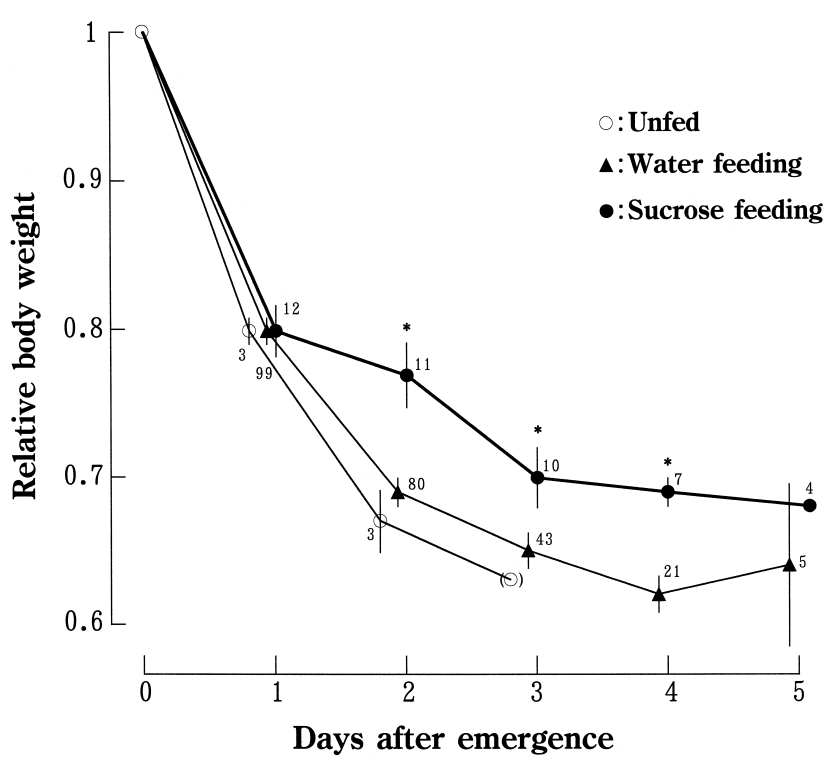

Fig. 1. Age specific changes in the relative weight of unfed virgin males (open circle), virgin males only fed water (triangle) and those fed on the $20 \%$ sucrose solution (solid circle) [ \pm SE]. The numbers beside the symbols show sample size. ${ }^{*} \mathrm{P}<0.01$ in comparison to the relative body weight of males only fed water (Mann-Whitney U-test) [2-day-old: $z=2.442$, 3-day-old: $z=2.406$, 4-day-old: $z=2.604]$.

unfed males in the first 3 days. However, they survived several days longer and maintained their body weight at about $65 \%$ of that of 0 -day-old males.

Males which were fed the $20 \%$ sucrose solution also became lighter as they aged. However, the weight of 2 day old males was significantly heavier than those fed only water. All males fed on sucrose solution survived to the end of the 5 day experiment. Consequently, sucrose enhances longevity and decreases body weight loss in adult males.

Fig. 2 shows that the daily intake (ca. $45 \mathrm{mg}$ per day) of males fed on water never exceeded $10 \%$ of their original weight. On the other hand, males fed on the sucrose solution had a significantly higher daily intake than males fed only water, and they ingested at least $20 \%$ of their original weight (ca. 90 $\mathrm{mg}$ of sucrose solution (=18 $\mathrm{mg}$ of sucrose)) each day.

We successfully paired 24 one-day-old males with virgin females. No males fed on water and sucrose solution. The copula duration lasted $51.4 \pm 2.9 \mathrm{~min}(\mathrm{SE})$. All males produced a spermatophore filled with white secretion and sperm in the females' bursa copulatrix. The weight of the spermatophores averaged $4.7 \pm 0.1 \mathrm{mg}$ (SE). During copulation, both males and females were inactive, suggesting that little weight loss occurred except for male ejaculates. Consequently, the spermatophore mass represents $1.3 \%$ of a male body mass.

All virgin males copulated irrespective of their age, though the longevity of water feeding males was short. After 2-days of age, most virgin males fed only water ejaculated a spermatophore in weight as similar to or lower than that of 1-dayold males (Fig. 3). However, at the respective ages, virgin males fed on the sucrose solution produced significantly larger spermatophores than those fed water only. There was a posi- 


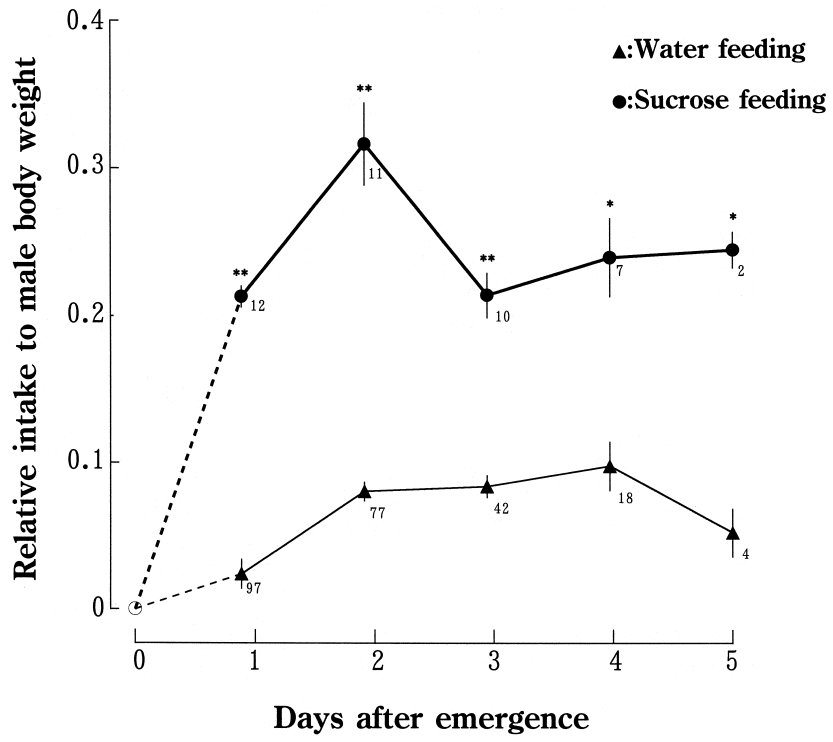

Fig. 2. The change in relative intake of water (triangle) and the $20 \%$ sucrose solution (solid circle) to the body weight of virgin males at emergence $[ \pm S E]$. The numbers beside the symbols show sample size. ${ }^{*} \mathrm{P}<0.05$ and ${ }^{* *} \mathrm{P}<0.01$ in comparison to the relative intake of water (Mann-Whitney U-test) [1-day-old: $z=6.033$, 2-day-old: $z=5.703$, 3-day-old: 5.027, 4-day-old: $U=12$, 5-day-old: $U=0]$. tive relationship between the amount of sucrose ingested and the weight of the spermatophore ejaculated by the virgin males.

We attempted to re-mate by hand pairing males that had copulated on the day after emergence. None of these males mated if the pairing attempt was made within $24 \mathrm{hr}$ of the first copulation. Some of them failed to be in tandem, however, there was no difference between males only fed water and those fed on the sucrose solution (Table 1). There were several females without spermatophore in the bursa copulatrix. Only $30 \%$ of the former males succeeding to be in tandem ejaculated a spermatophore, compared to $82 \%$ of the latter males. Therefore, the males feeding on sucrose solution were more successful at copulation than water feeding males, though the probability was less than 0.05 . We observed that the older males feeding on water tended to fail to ejaculate. Such males were discarded from further experiments.

The copula duration at second matings of males only fed water was 48 min (Table 1), which was not significantly different to the first matings $(U=38.0$, n.s. $)$. In contrast, the copula duration of males fed sucrose solution at the second mating was significantly longer than that of the first mating and of the second matings of males only fed water.

Fig. 4 shows that the second spermatophore produced

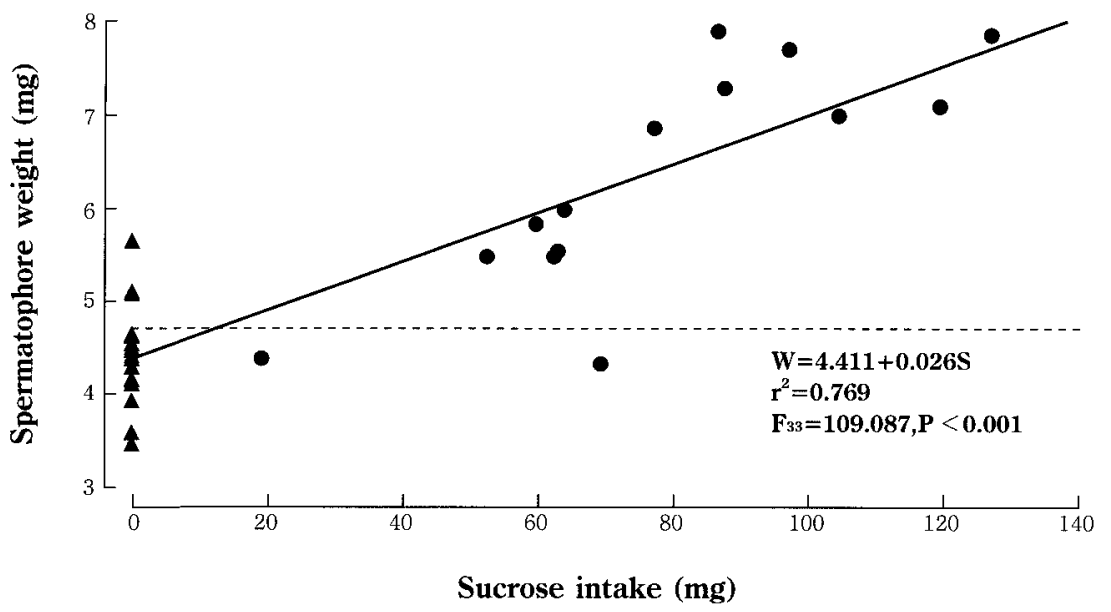

Fig. 3. The relationship between sucrose intake $(\mathrm{S} \mathrm{mg})$ and the spermatophore weight $(\mathrm{W} \mathrm{mg})$ ejaculated by virgin male. The dotted line shows the mean weight of spermatophore ejaculated by males on the day following emergence. Circles and triangles represent the males feeding on sucrose solution of $20 \%$ and water, respectively.

Table 1. The percentage of success and the copula duration at the second mating using the hand-pairing method for males feeding on sucrose solution compared to males feeding on water. Each parenthesis indicates the number of successful males of those examined.

\begin{tabular}{llll}
\hline Males feeding on & Water & Sucrose & \multicolumn{1}{c}{$\mathrm{G}_{\text {adj }}$} \\
\hline In tandem & $66.7(10 / 15)$ & $84.6(11 / 13)$ & 0.572 n.s. \\
Spermatophore insemination & $30.0(3 / 10)$ & $81.8(9 / 11)$ & $5.620 \quad \mathrm{P}<0.025$ \\
Success of copulation & $20.0(3 / 15)$ & $69.2(9 / 13)$ & $3.431 \quad 0.1>\mathrm{P}>0.05$ \\
\hline Copula duration $( \pm$ SE) & $47.8 \pm 4.99(3)$ & $66.3 \pm 3.87^{\mathrm{a}}(9)$ & $\mathrm{U}=2.0, \mathrm{P}<0.05$ \\
\hline
\end{tabular}

a: Significantly different from the copula duration at the first mating of 1 -day-old males $(U=30.0, P<0.001)$ 


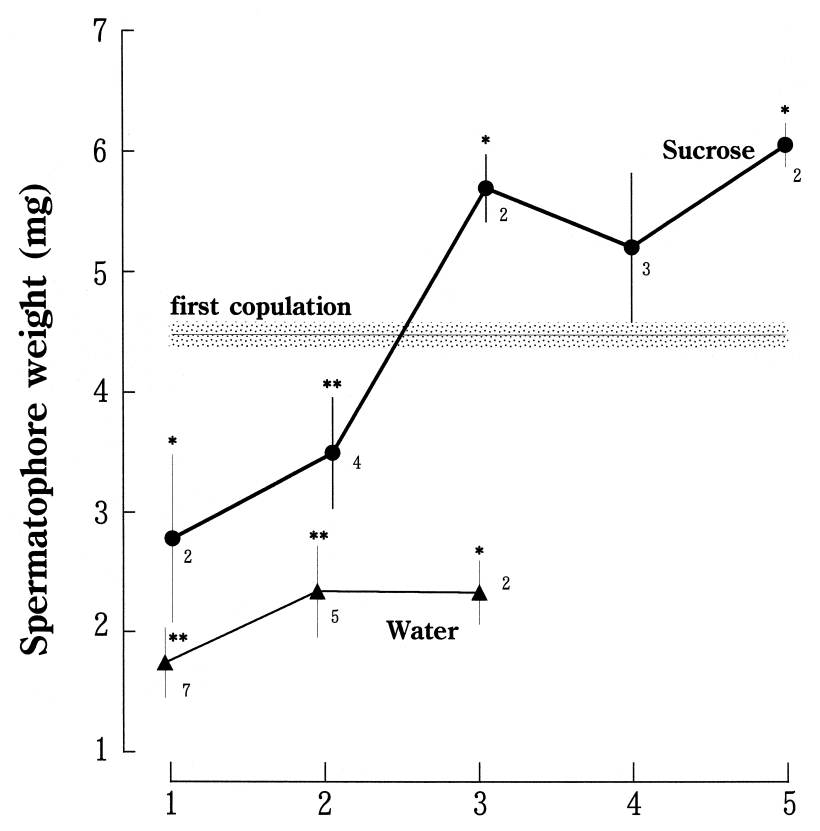

Days after first copulation

Fig. 4. The weight of the spermatophore $(\mathrm{mg}, \pm \mathrm{SE})$ produced at the second copulation in relation to time elapsed since the first copulation. The shaded area including a thin line shows the spermatophore weight ejaculated at the first copulation by virgin males the day after emergence with SD. Circles and triangles represent the males fed on sucrose solution and only water, respectively, during the resting period, which is indicated as the days following the first copulation. That is, 0 days means that a male copulated on two successive days. The numbers beside the symbols show sample size. ${ }^{*} P<0.05$ and ${ }^{* *} P<0.01$ in comparison to the spermatophore weight at the first copulation (Mann-Whitney U-test) [For males fed on water, 1 day resting: $z=3.874$, 2 days resting: $z=3.359$, 3 days resting: $z=2.154$; For males fed on sucrose solution, 1 day resting: $z=2.305,2$ days resting: $z=2.492,3$ days resting: $z=1.953,5$ days resting: $z=2.153$. by males fed water was around $2 \mathrm{mg}$, which was significantly lighter than that of the first copulation, irrespective of their resting period. Because the resting period did not increase the weight of the spermatophore, a male's ability to produce spermatophores during their lifetime without feeding on sucrose solution is apparently limited by the quantity of nutrients accumulated during the larval stage.

The intake of sucrose solution increased the weight of the spermatophore at the second copulation (Fig. 4) but only if these were two days between the first and second copulation. The resting period therefore increased weight of the second spermatophore to about $6 \mathrm{mg}$, which was significantly higher than that at the first copulation.

Fig. 5 shows the relationship between the amount of sucrose ingested and the weight of the second spermatophore relative to the first. When males were only fed water, the second spermatophore was about half the size of the first. However, feeding on sucrose increased the second spermatophore to as much as 1.5 times that of the first spermatophore. The regression line indicates that ingesting $77.57 \mathrm{mg}$ of sucrose (or $390 \mathrm{mg}$ of $20 \%$ sucrose solution) allows a male to produce a second spermatophore that is of similar weight to the first. Given that males consume about $90 \mathrm{mg}$ of solution daily, they need about 4.3 days to produce a second spermatophore of the same weight as the first. However, the calculation may be underestimated, since males in the field are constrained by time in their feeding and the amount they ingest may be smaller than in a laboratory with restricted flight activity.

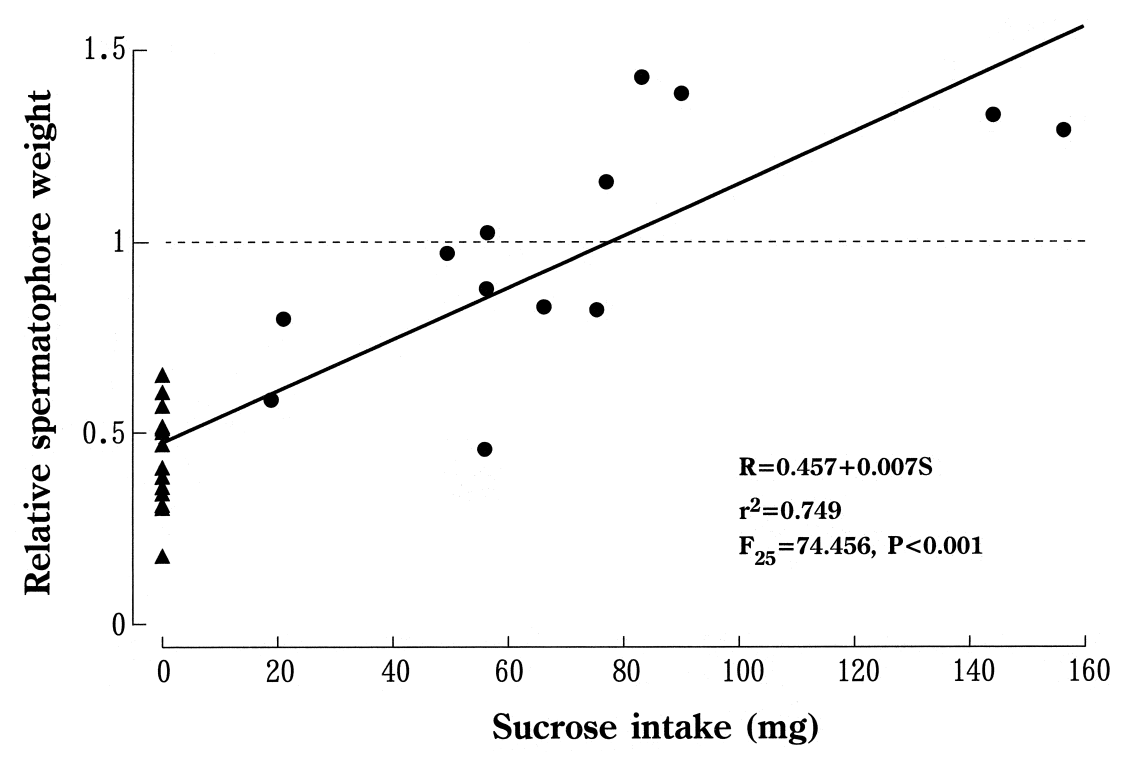

Fig. 5. The relationship between sucrose intake $(S)$ during the resting period and the relative weight of the spermatophore (R) ejaculated at the second copulation. The dotted line is that expected if the weight of the spermatophore at the first and second copulations is the same. The circles and triangles represent males feeding on sucrose solution and water, respectively, during the resting period. 


\section{DISCUSSION}

Wickman (1985) observed that in Satyrid butterflies males determined the mating duration. Copula duration is considered to have evolved in the context of sexual selection (Watanabe et al., 1997), to protect a male's sperm investment from conspecific males competing for fertilization (e.g. Parker 1970). In this study, a pair of $P$. xuthus typically separated about 50 min after the start of copulation and a spermatophore was formed in the female's bursa copulatrix. At the second mating the copula duration did not vary for males only fed water, suggesting that forming a spermatophore in the bursa copulatrix requires at least 50 min regardless of size. However, males fed on the sucrose solution copulated for a long time at the second mating probably due to the larger spermatophore size. Therefore, prolonged mating has a function as a spermatophore transfer (Oberhauser, 1989; Watanabe et al., 1997), though the difference in spermatophore size was due to the varying ability of males to transfer the spermatophore itself.

Fat bodies are a reservoir of nutrients derived from the larval stage and are used in adult somatic maintenance (Watanabe 1992), in female egg production (e.g. Boggs, 1997) and male spermatophore production. Males of polyandrous species appear to be able to produce more than one highquality ejaculate (Bissoondath and Wiklund, 1996b). In the present study, even males only fed on water were able to produce two spermatophores, probably using resources in the fat body. Since the spermatophore weight was similar among 1-day-old males on different feeding regimes, the resources for spermatophore production were not derived from sugar eaten by the males, but either from fat bodies or other internal substances, both of which are derived from the larval stage. Oberhauser (1989) stated that most of the spermatophore nitrogen must come from larval resources and could represent an important limiting resource for males.

Wedell (1996) showed that males of the comma butterfly, Polygonia c-album, donate between $38 \%$ and $47 \%$ of their resources at their first mating and keep their investment per spermatophore constant. Males produce the same-sized spermatophore 2 days after their first copulation (Svärd and Wiklund, 1989), which suggests that males allocate the same amount of resources per spermatophore, possibly at the same cost. However, ejaculate size typically declines with successive matings (Carroll, 1994; Kandori and Ohsaki, 1996; Lederhouse et al., 1990).

In the present study, the size of spermatophores produced at second matings increases with the mating interval. Males only fed water ejaculated a smaller spermatophore at the second copulation than that at the first (Fig. 4), suggesting that nutrients derived from the larval stage have the potential to produce 1.5 spermatophores of 'normal' size, though the success ratio for double copulations was only $20 \%$ (Table 1 ). Svärd and Wiklund (1986) showed that virgin males of $P$. machaon deliver ejaculates that are twice as big as any ejaculate transferred at later matings. Smaller spermatophores are less costly for males to produce. Therefore, a male's reproductive success may be limited by the lack of ejaculate and not by availability of females. Furthermore, consecutive matings are most likely to cause the depletion of accessory gland substances. A similar decrease in spermatophore size with an increasing number of matings has been observed in a variety of Lepidoptera (e.g. Sims, 1979; Boggs and Watt, 1981; Svärd and Wiklund, 1989). Certain elements of accessory gland secretions are known to influence the movements of sperm in females (Leopold, 1976) by stimulating contractions in the females' genital ducts and directly influencing sperm mortality (e.g. Carroll, 1994).

In $P$. xuthus, there is a risk that a male's mate will mate again before oviposition. Watanabe and Nozato (1986) showed that the females of this species are polyandrous, and may mate 3 times during their life (more than 2 weeks). Males may reduce this risk by producing large spermatophores. The length of a female's refractory period between successive matings is positively related to spermatophore size (e.g. Sugawara 1979; Rutowski, 1980; Oberhauser, 1989; Wiklund and Kaitala, 1995), and renders females unreceptive to additional matings for a longer period of time (Carroll, 1994). Furthermore, females with depleted spermatophores may have their egg production limited by lack of sperm or nutrients in the accessory gland secretions they receive during copulation (Rutowski, 1980). Consequently, males that transfer large ejaculates appear to be rewarded with increased paternity.

Svärd and Wiklund (1986) reported that spermatophores in $P$. machaon decreased to about half of their initial size with time having elapsed since the first mating. The ejaculates produced by males of Pierid butterflies re-mated on the same day were the smallest and contained the least amount of protein, but then increased in size and protein content with the number of days between matings (Bissoondath and Wiklund, 1996a). Our studies revealed that there was also a rapid recovery of spermatophore size at the second copulation in males of $P$. xuthus feeding on sucrose solutions. Since the long resting period increased the spermatophore weight, some of which were larger than those at the first mating, it follows that males use sucrose in the production of spermatophore and, partly for body maintenance. Boggs (1997) stated that if nutrients from adult feeding exceed expenditures, adult-derived nutrients may be stored, therefore, joining juvenile-derived nutrients. Among lepidopteran species, at least, the proportion of resources stored as reserves vs. those used immediately is linked to the expected reproductive output minus adult resource intake (Boggs, 1981; Karlsson, 1994). Therefore, the intake of sucrose is important in increasing male investment, because a certain amount of sucrose taken by older experienced males may be advantageous due to the large spermatophore ejaculated, though the copula duration increased somewhat. Bissoondath and Wiklund (1996b) observed that in Pieris rapae there was no effect of mating history on the mass or protein content of ejaculates when males fed on the $25 \%$ sugar solution. For $P$. xuthus sucrose intake increased the spermatophore mass produced by old virgin 
males.

Spermatophore size could influence female reproductive output if it limited the amount of sperm transferred (e.g. Sims, 1979) as well as the level of male-donated nutrients. An increasing longevity of females in male donating species has been documented in several butterfly species (Rutowski and Gilchrist, 1986; Wiklund et al., 1993), which indicates that male donations in paternally investing species may offset some of the cost of reproduction to females. Limited sperm transfer may also potentially affect the reproductive output of females. However, a male always transfers an excess of eupyrene sperm to inseminate all of a female's eggs at one mating irrespective of the mating history in Pieris rapae (Watanabe et al., 1998). Svärd and Wiklund (1991) found no impact of successive male matings on the reproductive output of females, despite smaller spermatophores. Thus, male-donated nutrients can be most important to females in delaying re-mating, though the nutrients can eventually increase the female's reproductive output (Watanabe, 1988).

$P$. xuthus males might benefit from exclusively feeding on nectar to recover the ability to produce spermatophore for a few days, instead of searching for females to immediately copulate with following the first copulation. Marshall (1982) stated that the degree to which a male is willing to invest should be a reflection of the ratio of the cost of future matings. If it is true, not all males flying in the field can be regarded as reproductive males. The operational sex ratio in the field must be re-considered.

\section{ACKNOWLEDGEMENTS}

We would like to thank Dr. R. L. Rutowski and Dr. C. Boggs for their critical review of the manuscript. We are also grateful to $Y$. Nakanishi, T. Imoto, M. Nishimura, M. Tsuchiya, A. Hachisuka, A. Ichioka and A. Fujii for their assistance. This work was supported in part by Grant-in-Aid from the Ministry of Education, Science and Culture, Japan (No. 01540545 and No. 10640612) to M. Watanabe.

\section{REFERENCES}

Arms K, Feeny P, Lederhouse RC (1974) Sodium: stimulus for puddling behavior by tiger swallowtail butterflies, Papilio glaucus. Science 185: 372-374

Baker HG, Baker I (1973) Amino-acids in nectar and their evolutionary significance. Nature 241: 543-545

Bissoondath CJ, Wiklund C (1996a) Effect of male mating history and body size on ejaculate size and quality in two polyandrous butterflies, Pieris napi and Pieris rapae (Lepidoptera: Pieridae). Functional Ecology 10: 457-464

Bissoondath CJ, Wiklund C (1996b) Male butterfly investment in successive ejaculates in relation to mating system. Behav Ecol Sociobiol 39: 285-292

Boggs CL (1981) Nutritional and life-history determinants of resource allocation in holometabolous insects. Am Nat 117: 692-709

Boggs CL (1990) A general model of the role of male-donated nutrients in female insect's reproduction. Am Nat 136: 598-617

Boggs CL (1997) Reproductive allocation from reserves and income in butterfly species with differing adult diets. Ecology 78: 181191

Boggs CL, Gilbert LE (1979) Male contribution to egg production in butterflies: Evidence for transfer of nutrients at mating. Science 206: 83-84

Boggs CL, Watt WB (1981) Population structure of pierid butterflies. IV. Genetic and physiological investment in offspring by male Colias. Oecologia 50: 320-324

Carroll AL (1994) Interactions between body size and mating history influence the reproductive success of males of a tortricid moth, Zeiraphera canadensis. Can J Zool 72: 2124-2132

Carroll AL, Quiring DT (1992) Sucrose ingestion by Zeiraphera canadensis Mut. and Free. (Lepidoptera: Tortricidae) increases longevity and lifetime fecundity but not oviposition rate. Can Entomol 124: 335-340

Dewsbury DA (1982) Ejaculate cost and male choice. Am Nat 119: $601-610$

Heinrich B, Raven PH (1972) Energetics and pollination ecology. Science 176: 597-602

Kaitala A, Wiklund C (1995) Female mate choice and mating costs in the polyandrous butterfly Pieris napi (Lepidoptera: Pieridae). J Insect Behav 8: 355-363

Kandori I, Ohsaki N (1996) Male mating behavior in relation to spermatophore transfer in the white cabbage butterfly. Res Popul Ecol 38: 225-230

Karlsson B (1994) Feeding habits and change of body composition with age in three nymphalid butterfly species. Oikos 69: 224-230

Lederhouse RC, Ayres MP, Scriber JM (1990) Adult nutrition affects male virility in Papilio glaucus L. Functional Ecology 4: 743-751

Leopold RA (1976) The role of male accessory glands in insect reproduction. Ann Rev Entomol 21: 199-221

Marshall LD (1982) Male nutrient investment in the Lepidoptera: What nutrients should males invest? Am Nat 120: 273-279

Marshall LD (1985) Protein and lipid composition of Colias philodice and $C$. eurytheme spermatophores and their changes over time (Pieridae). J Res Lepid 24: 21-30

Muraoka K, Watanabe M (1997) A new technique for measuring nectar intake of pierid butterflies, Pieris rapae and $P$. melete (Lepidoptera, Pieridae), and optimal sugar concentration. Jpn J Ent 65: 225-232

Murphy DD, Launer AE, Ehrlich PR (1983) The role of adult feeding in egg production and population dynamics of the checkerspot butterfly Euphydryas editha. Oecologia 56: 257-263

Oberhauser KS (1988) Male monarch butterfly spermatophore mass and mating strategies. Anim Behav 36: 1384-1388

Oberhauser KS (1989) Effects of spermatophores on male and female monarch butterfly reproductive success. Behav Ecol Sociobiol 25: 237-246

Oberhauser KS (1992) Rate of ejaculate breakdown and intermating intervals in monarch butterflies. Behav Ecol Sociobiol 31: 367373

Parker GA (1970) Sperm competition and its evolutionary consequences in the insects. Biol Rev 45: 525-567

Pivnick KA, McNeil JN (1985) Effects of nectar concentration on butterfly feeding: measured feeding rates for Thymelicus lineola (Lepidoptera: Hesperiidae) and a general feeding model for adult Lepidoptera. Oecologia 66: 226-237

Rutowski RL (1980) Courtship solicitation by females of the checkered white butterfly, Pieris protodice. Behav Ecol Sociobiol 7: 113-117

Rutowski RL, Gilchrist GW (1986) Copulation in Colias eurytheme (Lepidoptera: Pieridae): patterns and frequency. J Zool Lond (A) 209: 115-124

Scriber JM, Lederhouse RC (1988) Hand-pairing of Papilio glaucus glaucus and Papilio pilumnus (Papilionidae) and hybrid survival on various food plants. J Res Lepid 27: 96-103

Sims SR (1979) Aspects of mating frequency and reproductive maturity in Papilio zelicaon. Amer Midl Nat 102: 36-50

Stern VM, Smith RF (1960) Factors affecting egg production and oviposition in populations of Colias philodice eurytheme Boisduval 
(Lepidoptera: Pieridae). Hilgardia 29: 411-454

Sugawara T (1979) Stretch reception in the bursa copulatrix of the butterfly, Pieris rapae crucivora, and its role in behaviour. J Comp Physiol 130: 191-199

Svärd L, Wiklund C (1986) Different ejaculate delivery strategies in first versus subsequent matings in the swallowtail butterfly Papilio machaon L. Behav Ecol Sociobiol 18: 325-330

Svärd L, Wiklund C (1989) Mass and production rate of ejaculates in relation to monandry/polyandry in butterflies. Behav Ecol Sociobiol 24: 395-402

Svärd L, Wiklund C (1991) The effect of ejaculate mass on female reproductive output in the European swallowtail butterfly, Papilio machaon (L.) (Lepidoptera: Papilionidae). J Insect Behav 4: 33 41

Watanabe M (1988) Multiple matings increase the fecundity of the yellow swallowtail butterfly, Papilio xuthus L., in summer generations. J Insect Behav 1: 17-29

Watanabe M (1992) Egg maturation in laboratory-reared females of the swallowtail butterfly, Papilio xuthus L. (Lepidoptera: Papilionidae), feeding on different concentration solutions of sugar. Zool Sci 9: 133-141

Watanabe M, Koizumi H, Suzuki N, Kiritani K (1988) Studies on ecology and behavior of Japanese black swallowtail butterflies. VII. Nectar of a glory tree, Clerodendron trichotomum, as a food resource of adults in summer. Ecol Res 3: 175-180

Watanabe M, Nakanishi Y, Bon'no M (1997) Prolonged copulation and spermatophore size ejaculated in the sulfur butterfly, Colias erate (Lepidoptera: Pieridae) under selective harassments of mated pairs by conspecific lone males. J Ethol 15: 45-54
Watanabe M, Nozato K (1986) Fecundity of the yellow swallowtail butterflies, Papilio xuthus and $P$. machaon hippocrates, in a wild environment. Zoological Science 3: 509-516

Watanabe M, Sato K (1993) A spermatophore structured in the bursa copulatrix of the small white Pieris rapae (Lepidoptera: Pieridae) during copulation, and its sugar content. J Res Lepid 32: 26-36

Watanabe M, Wiklund C, Bon'no M (1998) The effect of repeated matings on sperm numbers in successive ejaculates of the cabbage white butterfly Pieris rapae (Lepidoptera: Pieridae). J Insect Behav 11: 559-570

Wedell N (1996) Mate quality affects reproductive effort in a paternally investing species. Am Nat 148: 1075-1088

West DA (1983) Hand-pairing of Battus philenor (Papilionidae). J Lepid Soc 37: 90

Wickman P-O (1985) Male determined mating duration in butterflies? J Lepid Soc 39: 341-342

Wiklund C, Kaitala A (1995) Sexual selection for large male size in a polyandrous butterfly: the effect of body size on male versus female reproductive success in Pieris napi. Behav Ecol 6: 6-13

Wiklund C, Kaitala A, Lindfors V, Abenius J (1993) Polyandry and its effect on female reproduction in the green-veined white butterfly (Pieris napi L.). Behav Ecol Sociobiol 33: 25-33

(Received June 4, 1998 / Accepted October 16, 1998) 